ISSN: 2224-0616

Int. J . Agril. Res. Innov. \&Tech. 5(2): 70-74, December, 2015 Available online at http://www.ijarit.webs.com

\title{
IMPROVEMENTS OF HARROWS WEAR RESISTANCE
}

\section{Warouma Arifa*, Viktor Aulin² and Igor Shepelenko²}

Received 28 October 2015, Revised 25 November 2015, Accepted 22 December 2015, Published online 31 December 2015

\begin{abstract}
Wear is the main reason for the loss of performance of the parts for agricultural machinery. It leads to the degradation of the soil working quality. This work aims to highlight the wear resistance of the harrows discs manufactured, consolidated and sharpened differently. The tests were conducted in the laboratory and the field of the Faculty of Exploitation and Repair of Agricultural Machinery of the State Technical University of Kirovograd (Ukraine) in 2015. The technical equipment consists of devices for consolidation by electric discharge and for measurement the linear wear of discs, a harrow, a sand test bed, a tractor and discs made of different materials and technologies. Some parameterized were collected during the laboratory test each 5 ha and up to 20 ha of operation and in the fields each 30 ha until the time limit of exploitation. The Laboratory tests have shown that after twenty (20) ha of operation, the wear resistance of the experimental discs made of steel $65 \mathrm{G}$ and consolidated by electric discharge with simultaneous grinding (sharpening angle of $30^{\circ}$ ) is 2.95 times higher than the discs in series made of steel 28MnB5. The field experiment gave the following results: According to agro technical requirements, the plowing depth limit of serial discs made of steel 28MnB5 was reached after an operating duration of 120 ha while for experimental discs made of steel 65G and consolidated by electric discharge with simultaneous grinding (sharpening angle of 30 degrees) this duration is of 156 ha. The diameter wear limit of experimental discs was reached after an operating duration of 179 ha against 154 ha for the serial ones. Therefore, the new technology can be applied during the manufacture and / or the repair of the discs.
\end{abstract}

Keywords: Consolidation by electric discharge, Discs, Operation time limit, Limit wear, Wear resistance, Self-sharpening

${ }^{1}$ Department of Rural Engineering \& Water and Forests, Dan Dicko Dan Koulodo University of Maradi, Niger

${ }^{2}$ Department of Agricultural Machinery Operating and Repair, National Technical University of Kirovograd, Ukraine

*Corresponding author's email: warouma@yahoo.com (Warouma Arifa)

\section{Introduction}

Wear is the main reason for the loss of performance of the parts for agricultural machinery. During the action of working parts of plowing machinery (WPPM) on the soil, the state of stress deformation changes and the initial structure of the soil is disturbed (Viktor and Warouma, 2013; Borak, 2013).

These processes significantly affect the friction and the wear of the working parts and the working quality of the soil. The Failures due to wear in modern conditions represent 80 to $90 \%$ of the total failures (Warouma, 1999; Severnev, 1972). One of the main tasks of the modern engineering is to improve the wear resistance of the parts operating under abrasive wear conditions (Tkachev, 1995; Khrushchev and Babichev, 1970; Kostecki et al., 1976).

The disc tillage implements (DTI) constitute about $40 \%$ of the total agricultural machinery (Tikhonov and Sidashenko, 2010; Strelbitsky, 1978). Because of wear, the nominal dimensions of the disc and its form undergo some changes that significantly affect the quality of work (Aulin and Borak, 2013; Sidorov, 2007; Bernstein, 2002). Therefore, it is necessary to maintain the shape and to improve the wear resistance of the working parts (WP) of the disc tillage implements (DTI).

The rapid wear of the outer diameter, the blunting of the cutting edge, as well as the change of the disc surface lead to increase the fuel and lubricant consumption, the degradation of the quality of work of the soil, an additional sharpening of the WP and replacement of worn parts or their restoration (Artem, 2001; Mikhalchenkov et al., 2006).

The choice of method for increasing the wear resistance must take into account that the wear on the WP of DTI has a selective (local) character because of the irregular nature of the soil pressure on WP (Aduov et al., 2009; Sidorov, 2007; Aulin and Borak, 2013).

When selecting the consolidation method of Disc Tillage Implements (DTI), it is important to take into account the need to achieve the selfsharpening effect. 
The technical requirements of the working parts to discs offer their manufacture with steel 65G or with its alternatives such as steels M76 and 45 have undergone a heat treatment to a lifetime of 39 to 44 HRC. The cost of the discs produced with steels of higher resistant to wear, in particular the steels $28 \mathrm{MnB5}$ and Earth Metal, is 2.0 to 2.3 times higher than that of the steels mentioned above, but they have a resistance to wear of 20 to $30 \%$ higher (Dudak, 2007). The use of metals and alloys of high quality is economically impossible, that's why the solution is the local search methods of curing of the surfaces of working pieces.

For agricultural machines operating in abrasive conditions, the following types of welding are performed: gas manual welding with the use of chopsticks from alloys Sormayt №1 type; solder powder; multi-electrode with electro conductive solder; by plasma welding; induction welding (Strelbitsky 1978; Aulin, 2013). In the field of agricultural machinery, $90 \%$ of all building work is carried out by induction welding (Strelbitsky, 1978). The main disadvantage of this method is the high cost of the materials used.

Constructive possibilities of improving the wear resistance of parts of agricultural machines are varied, but mainly boil down to the performance of the parts operating regime (Dudak, 2007). The main objective of this research is the identification of the materials and the technologies of manufacture and consolidation that are more resistant to abrasive wear.

\section{Materials and Methods}

\section{Materials}

Wear is composed of-

- A device for consolidation by electric discharge (CED) 01.10.016A

- A harrow of AKPIL brand

- A device for measuring the linear disc wear

- A sand test bed

- A tractor MTZ-80

The treatments as follows:

$\mathrm{T}_{1}$ : Serial discs manufactured with steel $28 \mathrm{MnB5}$

$\mathrm{T}_{2}$ : Experimental discs constructed with steel 65G and reinforced by electric discharge with simultaneous grinding (sharpening angle $17^{\circ}$ )

$\mathrm{T}_{3}$ : Experimental discs manufactured in steel 65G and consolidated with the electrode T-590

$\mathrm{T}_{4}$ : Experimental discs manufactured in steel 65G and consolidated by electric discharge with simultaneous grinding (sharpening angle of $30^{\circ}$ ).

\section{Methods}

The CED of the external surface of the discs by the device represented in Fig. 1 and laboratory tests were performed in the laboratory of the Faculty of Exploitation and Repair of Agricultural Machinery of State Technical University of Kirovograd (Ukraine) in 2015.

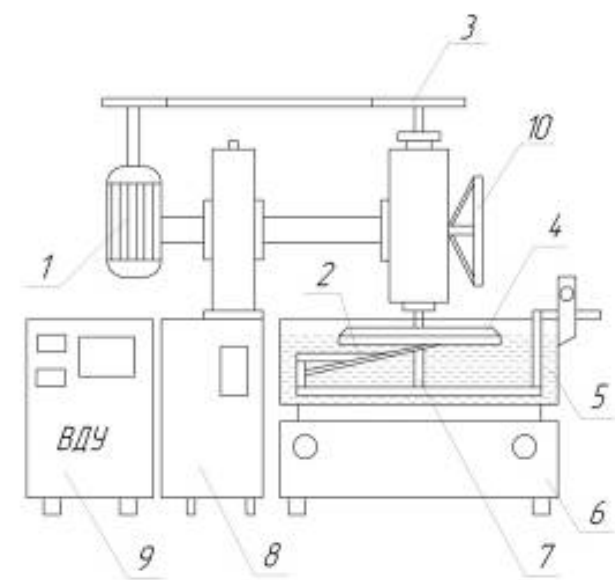

Fig. 1. Schematic of the consolidation device by electric discharge 01.10.016A: 1 - electric motor, 2 - part, 3 belt drive, 4 - electrode-tool, 5 - bathroom, 6 Training of the bath, 7 - cradle, 8 - control cabinet, 9 power supply, 10 - steering wheel adjustment

Laboratory tests for the determination of the intensity of the different plowshares wear were carried out on a sand test bench whose overview is shown on Fig. 2.

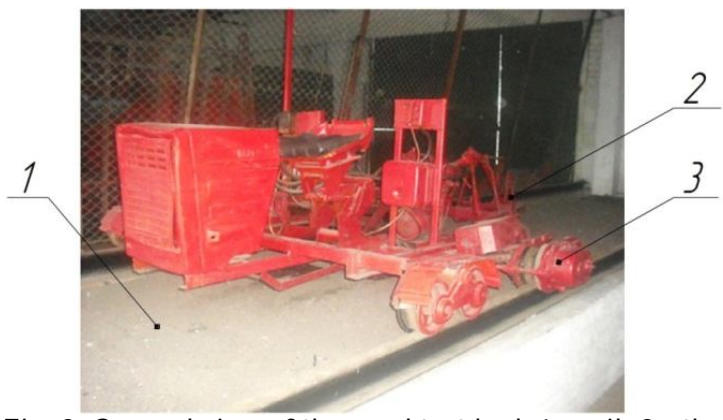

Fig. 2. General view of the sand test bed: 1 - soil, 2 - the coupling device of the discs, 3 - traction transfer device

To take into account of the effect of the soil type on the wear, soils with different physicomechanical structures were used during the exploitation (Table 1).

Table 1. Physico-mechanical properties of the soils

\begin{tabular}{lcc}
\hline Soil type & \multicolumn{2}{c}{ Average content, \% } \\
\cline { 2 - 3 } & Sand & Clay \\
\hline Sandy & 95 & 5 \\
Sandy clay & 80 & 20 \\
Loam & 50 & 50 \\
Clay & 10 & 90 \\
\hline
\end{tabular}


For reconciliation to the actual working conditions of DTI, the following conditions were maintained:

- After each experiment, the soil was changed and compacted;

- The distance between the edge of the disc and the sand bed of the groove was set to $400 \mathrm{~mm}$.

- The attack angle (the angle between the direction of the translational movement and the rotational plane of the disc) of discs during the experiment ranged from $20^{\circ}$ to $25^{\circ}$, the working speed is 7.5 to $15 \mathrm{~km} / \mathrm{h}$. The soil moisture was maintained between 6 and $8 \%$ and the hardness of the soil is 0.5 to $0.7 \mathrm{MPa}$.

The measurements were taken each five (5) hectares per disc. The measurement data were processed using the method of mathematical statistics.

Operating tests were conducted in 2014 in an experimental field of the said Faculty. Soil moisture is from 9 to $25 \%$, the working speed of the harrow (Fig. 3) is from 8 to $15 \mathrm{~km} / \mathrm{h}$ with a plow depth between 8 and $20 \mathrm{~cm}$. During the experiment, it was also performed to monitor the effect of self-sharpening.

The measurements were taken each thirty (30) hectares for a single disc. The measurement data were processed using the method of mathematical statistics.

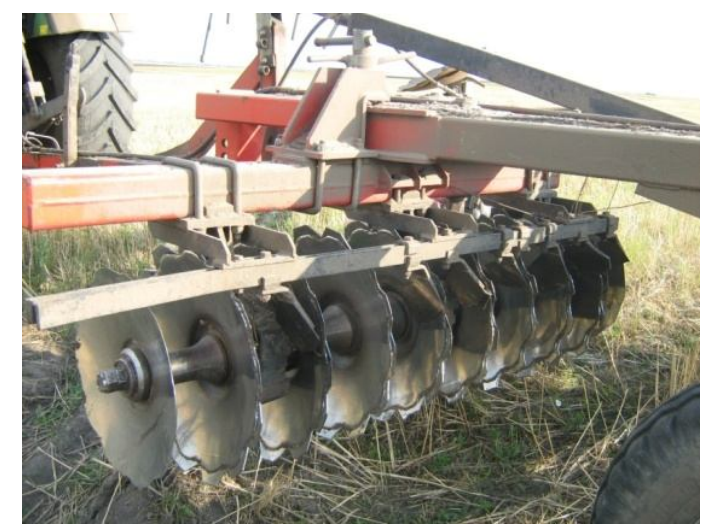

Fig. 3. General view of a section of the harrow AKPIL

For both tests (laboratory and field), the linear wear of the disc diameter was determined by the device schematically shown in Fig. 4.

The measurements were performed in the following order:

- The discs was installed on the device and photographed, the data were transmitted to a computer and processed using the 3DV9 software;
- After a certain time of operation, the disc was photographed and using a computer it was determined the difference between the initial and final edges of the disc.

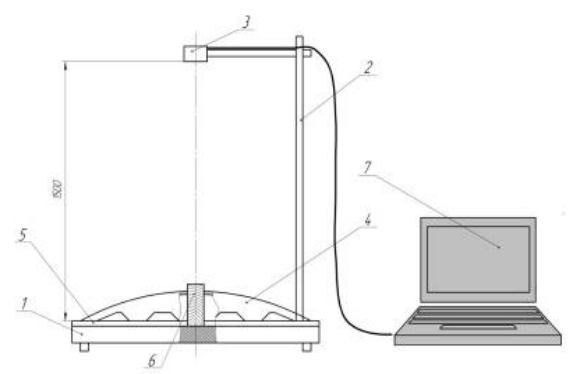

Fig. 4. Device for determining the linear wear diameter discs: 1 - base, 2 - tripod, 3 - digital camera, 4 - Disc, 5grid with coordinates, 6- computer

This method allows to observe the dynamics of linear wear change and the shape of the WP of DTI during test operation.

During the experiment, it was also determined one of the performance indicators (working depth) execution of the technological process in accordance with the standard state 74.3-37-155: 2004.

To determine the need for sharpening of the discs, the reference values of the limits criteria of the blades have been defined (Table 2).

Table 2. Indicator of the condition limit of discs blade requiring sharpening

\begin{tabular}{ll}
\hline Designation of theindicator & Value \\
\hline $\begin{array}{l}\text { Sharpening angle of the blade, } \\
\text { degrees }\end{array}$ & $36-42$ \\
$\begin{array}{l}\text { Blade thickness at a distance of } 1 \mathrm{~mm} \\
\text { from the top of the blade, } \mathrm{mm}\end{array}$ & $1.5-2.2$ \\
\hline
\end{tabular}

\section{Results}

The laboratory tests (Fig. 5) allowed to have the first clues on the performance of the discs used. The linear wear intensity of the discs represented in this figure shows that after 20 ha of operation, the largest wear was observed at the level of serial discs manufactured in steel 28MnB5 and represented $18 \mathrm{~mm}$, while the minimal wear (6.1 $\mathrm{mm}$ ) was observed at the level of experimental discs manufactured in steel $65 \mathrm{G}$ and consolidated by electric discharge with simultaneous grinding (sharpening angle of $30^{\circ}$ ). Thus, the wear resistance of the experimental discs is 2.95 times higher than that of discs in series. 


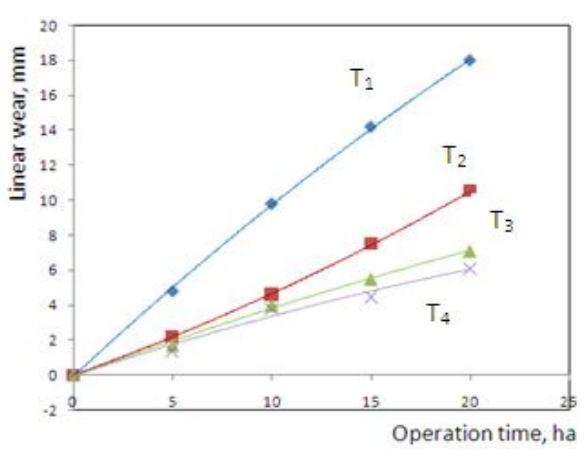

Fig. 5. Linear wear of discs

Linear wear of the serial and experimental discs resulting from fields' work are represented in the Fig. 6.

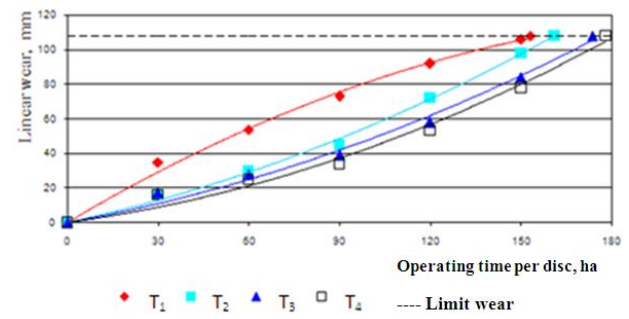

Fig. 6. Dependence of wear of the working parts of tillage machines discs depending on the operating life

It has been observed that, during operation, the manufactured discs with steel 28MnV5 began blunting after exploitation of 118 ha per disc. For discs reinforced by electric discharge with a sharpening angle of $17^{\circ}$, it was observed excess of output of the hard layer and its fracture when interacting with hard elements into the soil. For consolidated discs by electric discharge with a sharpening angle of $30^{\circ}$, during the operation, it has been observed the self-sharpening effect of the blade of the discs, which has increased the operating time of the discs consolidated by electric discharge until the announcement of the state limit of wear. This implies that during the entire operation the discs were not sharpened. Fig. 7 shows that during operation, the working depth decreases.

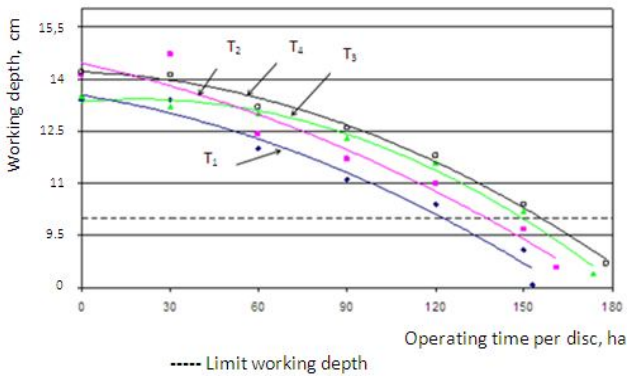

Fig. 7. Dependence of the working depth of the discs in accordance with the operating time
For the working depth, discs in series manufactured in steel 28MnB5 have reached the limit of agro-technical requirements after an operating time of 120 ha while for the experimental discs made of steel 65G and consolidated by electric discharge with simultaneous grinding (angle grinding of $30^{\circ}$ ) this time is $156 \mathrm{ha}$, above these values, for each of the above discs, the quality of the plowing will be disturbed to the extent that the plowing depth decreases. The time limit of operating discs is shown on Fig. 8.

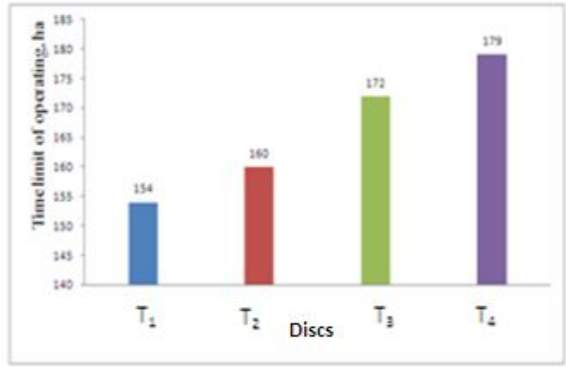

Fig. 8. Time limit of operating discs

The Fig. 8 shows that the most operating period (179 ha) was observed at the level of the experimental discs manufactured in steel 65G and consolidated by electric discharge with simultaneous grinding (sharpening angle of $30^{\circ}$ ) while the discs in series manufactured in steel 28MnB5 presented the smallest operation period (154 ha).

\section{Discussion}

The laboratory tests allowed to notice that after twenty (20) ha of operation, the wear resistance of experimental discs manufactured in steel 65G and consolidated by electric discharge with simultaneous grinding (sharpening angle of $30^{\circ}$ ) is 2.95 time higher than that of discs in series manufactured in steel 28MnB5. These laboratory results are different from those of Bernstein (2002) where the wear resistance of experimental discs is 3.3 times higher than that of discs in series. This is explained by the fact that, in one hand, the consolidation method, used are not the same, and on the other hand, the operating time is 15 ha against 20 ha for this experiment. But these results are confirmed by those of field operation because these experimental discs have reached the limit of agro-technical requirements in terms of labor depth after 156 ha of operation while the discs in series after 122 ha only. In addition, it has been observed that the most operating time limit with the experimental discs is 179 ha against 154 ha for the experimental discs, so a difference of 25 ha by disc. These results look like those of Tikhonov and Sidashenko (2010), where the difference is of 23 ha by disc. The graphic analysis of the figure 6 
shows the non- homogeneity of the material in depth leads to the change of the wear nature. To all tested discs in the fields, the state of wear limit is noticed with the decrease of the diameter until $546 \mathrm{~mm}$. For all discs, the criteria of the first case of limit state is the diametral wear which in return leads to non- respect of agro technical requirements. The experimental tests have shown that the sharpening angle for the most optimal method is $30^{\circ}$. These numerals look like those of Bernstein (2002) where the sharpening optimal angle is between 28 and $30^{\circ}$, but contrary to those obtained by Aduov et al. (2009) where the sharpening optimal angle is between 16 and $26^{\circ}$. During the operation (Fig.7), the working depth decreases. This is due to the decrease of disc diameter because of the wear.

\section{Conclusion}

The results of the tests have shown that experimental discs manufactured in steel 65G and reinforced by electric discharge with simultaneous sharpening (sharpening angle $30^{\circ}$ ) are lifelong. The wear resistance of the experimental discs, for the laboratory test is 2.95 time higher than that of discs in series manufactured in steel 28MnB5. As far as the tests in fields are concerned, the experimental discs have an operating time limit per disc of 25 ha more than those in series do. The selfsharpening phenomenon was observed all along the operation period of these discs and the shape of the discs remain almost unchanged. This consolidation method can be used during the manufactured and/or the rectification of discs harrow. Meanwhile, it will be interesting to do the same tests with the plough discs because they are also very solicited in the working soil and with regard to their dimensions and their working depth that can be higher; they are well disposed to abrasive wear. For a production program of 80.000 discs per year, the economic impact would be about 241.000 US dollars.

\section{References}

Artem, A.N. 2001. Optimization of parameters of working bodies of tillage implements and seeding. Improved technologies and techniques in agriculture. Barnaul. pp. 5557.

Aduov, M.A. Kapov, S.N. and Kaspakov, E.Z. 2009. Model of the interaction of the blade profile with the ground. J. Sci. Agrarian Univ. 4(5): 238-245.

Aulin, V.V. 2013. State of the self-organization of soil and regularity of wear of working elements of tillage implements. Problems of tribologie. J. Khmelnitsky Univ. KNU. 1: 114119.

Aulin, V.V. and Borak, K.V. 2013. Improving the wear resistance of the working members to tillage implements discs with the implementation of the effect of selfsharpening. Proceedings of the Scientific Conference XII and international practice. Novocherkassk. - YURGPU (NPI): pp. 50-58.

Bernstein, D.B. 2002. Wear by abrasion of the blade and disc harrow performance. Tractors and farm machinery. M: J. Mech. Eng. N. 6: 39-42.

Borak, K.V. 2013. Improved wear resistance scratch discs soil electric discharge. Doctoral Thesis. Agrarian State Technical University of Kharkov. 217p.

Dudak, S.M. 2007. Disc Work Tools: Key parameters and characteristics. Mechanization and electrification of agriculture. 91: 368-371.

Khrushchev, M.M. and Babichev, M.A. 1970. Abrasive wear. Nauca, Moscow. Science. 252p.

Kostecki, B.I. Strel'nikov, B.P. and Tatsiy, V.G. 1976. Wear and durability of wearing parts prediction. Problems of friction and wear. K:. Technique 10: 10-15.

Mikhalchenkov, A.M., Tyureva, A.A. and Parshikov, P.A. 2006. Improving the wear resistance of the discs through the consolidation of the most likely areas of wear. Collection of scientific work. National Agricultural Academy Briansk. 1: 234-239.

Severnev, M.M. 1972. Wear parts for agricultural machinery. - L.: Kolos. 288p.

Sidorov, S.A. 2007. Improving the longevity and performance of working bodies of plowing machines and tools used in agriculture and forestry. Doctoral Thesis. Russian State Agricultural University - Moscow. 441p.

Strelbitsky, V.F. 1978. Disc tillage machines. Mechanical Engineering.-M.: Kolos. 135p.

Tikhonov, D.A. and Sidashenko, A.I. 2010. Repair technology system of the blade discs of tillage implements. pp. 180-183. In: Conference of $\mathrm{PhD}$ students and teachers at the $4^{\text {th }}$ National Scientific and Practical of Ukraine. Kirovograd: KNTU.

Tkachev, V.N. 1995. Performances tools in the conditions of abrasive wear. Mechanical Engineering. Science. 336p.

Viktor, A. and Warouma, A. 2013. Research of the tense state of soil and workings organs of tillage machines and theirs influences on hauling resistance. J. Appl. Biosci. 72: 58835891.

Warouma, A. 1999. Rectification and consolidation of parts for agricultural machines using reloading powder torch gas Ceramico-métalliques. Coatings thèsis. State Technical University of Construction of Kirovograd. 137p. 